\title{
Risk Assessment of Engineering Project Financing Based on PPP Model
}

Qiuli Ma and Mingbo Sun

School of Management Engineering, Zhengzhou University, Zhengzhou 450001, China

\begin{abstract}
At present, the project financing channel is single, and the urban facilities are in short supply, and the risk assessment and prevention mechanism of financing should be further improved to reduce the risk of project financing. In view of this, the fuzzy comprehensive evaluation model of project financing risk which combined the method of fuzzy comprehensive evaluation and analytic hierarchy process is established. The scientificalness and effectiveness of the model are verified by the example of the world port project in Luohe city, and it provides basis and reference for engineering project financing based on PPP mode.
\end{abstract}

\section{Research background}

The problems faced by the development of city infrastructure in our country: The amount of investment of the city infrastructure construction is not sufficient. The capital is lack, and the investment unit is too single, and the financing method is too little in the urban infrastructure projects. Meanwhile, the city project investment and financing mechanism is not perfect, and the system is not complete. Furthermore, after the completion of the urban infrastructure projects, the lack of effective asset management mechanism, there is no proper operating institutions, resulting in a large number of funds invested did not make an inventory, and the construction of urban infrastructure has been far from meeting the great demand of the public.

From the above problems, the implementation of urban infrastructure projects in the process there is still a big problem. Government investment advantages are: quick, relatively large. Investment disadvantage is: the project economic efficiency is poor, the cost is more, and the loss is more serious. Now the problem is that the private sector has accumulated a large amount of money, and the government sector funds are obviously short, so a public-private partnership (PPP) came into being. PPP clever use of the advantages of the government departments and private enterprises respectively, and established the relationship of mutual cooperation, it introduced high efficiency and strong support of government departments and the management of advanced high technology, capital of private enterprises on the can provide policy and strong communication abilities, both sides reached the project than alone the obtained benefits.

In order to provide a reference for the risk identification of highway project under PPP financing mode, Cao Cong [1] constructed the risk identification system through two dimensions of the five steps, and emphasized the identification of key risk factors. Liu Yanwu [2] analyzed the causes of the financial risk of the PPP project, and found out the way to solve the risk. The difficulty and risk of Beijing Metro Line 4 risk sharing share basic program was 
analyzed according to the manifestation of the risks in each stage. Obtaining the results of risk sharing and quantitative analysis, and it provided theoretical support and practical guidance for the future of China's rail transit construction project PPP mode decision scientific and reasonable risk sharing [3]. Ai Bing and Lu Xiaocheng [4] analyzed the main PPP project risk, policy risk, exchange rate risk, technology risk, financial risk, operational risk, risk prevention measures of government project procurement PPP financing mode is mainly the government to speed up the change of role, strengthen the qualification certification and optimize the risk structure. Kong Qingli [5] studied the characteristics of PPP model, the particularity of risk allocation and the risk management methods of urban infrastructure projects, which had reference value for the promotion of PPP projects. Wu Aman [6] carried out a detailed analysis on the financing risk of the project through its structure, related elements, forms and typical case. It summarized the measures of financing risk prevention two and beneficial help to avoid the risk of project financing.

In this paper, the fuzzy comprehensive evaluation model of project financing risk which combined the method of fuzzy comprehensive evaluation and analytic hierarchy process is established. The risk of the project financing is assessed by the example of the world port project in Luohe city, and it provides basis and reference for engineering project financing based on PPP mode.

\section{Construction of risk assessment model of PPP model project financing}

(1) the weight of each risk factor is calculated:

The weight of each index can be calculated by the following formula:

$$
\omega_{\mathrm{i}}=\frac{\sqrt[n]{\prod_{j=1}^{n} a_{i j}}}{\sum_{k=1}^{n} \sqrt[n]{\prod_{j=1}^{n} a_{i j}}} \quad(\mathrm{i}=1,2,3, \ldots, \mathrm{n})
$$

$\omega$ is normalized:

$$
\omega=\frac{\omega_{i}}{\sum_{i=1}^{n} \omega_{i}}
$$

The first-level indexes B1 $\sim$ B8 can be calculated by this formula which relative to the total weight of the project target

A weight vector: ${ }^{\omega}=\left(\begin{array}{lllll}\omega_{1} & \omega_{2} & \ldots & \omega_{n}\end{array}\right)^{\mathrm{T}}$, similarly the second indicators relative to a target weight value can be got, In this way, the risk factors and the overall objective of the two level indicators are obtained.:

$$
\mathrm{W}_{\mathrm{I}(3)}=\sum_{j=1}^{8} p_{\mathrm{ij}}^{(3)} \omega_{j}^{(2)}
$$

(2) The consistency of the judgment matrix is tested

Consistency check need to do when there is only one principle in an engineering project. The proportion of the lump sum ratio according to the following formula is calculated: $C R=C I / R I$. When the index value $C R<0.1$, it can be considered that the judgment matrix of the engineering project is consistent with the consistency test. Where, $\mathrm{CI}=$ $\left(\lambda_{\max }-1\right) /(\mathrm{n}-1)$ that is the consistency of the indicators, and $\lambda_{\max }$ is the so-called matrix to determine the greatest characteristics of the root, after the solution of the value calculated by the following formula can be calculated: 


$$
\lambda_{\max }=\frac{1}{n} \sum_{j=1}^{n}(A W)_{i} / \omega_{i}=\frac{1}{n} \sum_{i=1}^{n}\left(\sum_{j=1}^{n} a_{i j} \omega_{j}\right) / \omega_{i}
$$

The $(A \omega)_{i}$ index value of the above formula can be expressed as the i component index of $A \omega$. The CI and RI are the average consistency index. In the following table 1, the random mean consistency index of the positive and negative matrix of the 1 to 15 order is given.

Table 1. Average random consistency index.

\begin{tabular}{|c|c|c|c|c|c|c|c|c|}
\hline Order number $\mathrm{n}$ & 1 & 2 & 3 & 4 & 5 & 6 & 7 & 8 \\
\hline RI & 0.00 & 0.00 & 0.52 & 0.89 & 1.12 & 1.26 & 1.36 & 1.41 \\
\hline Order number $\mathrm{n}$ & 9 & 10 & 11 & 12 & 13 & 14 & 15 & \\
\hline RI & 1.46 & 1.49 & 1.52 & 1.54 & 1.58 & 1.58 & 1.59 & \\
\hline
\end{tabular}

Using the fuzzy comprehensive evaluation method to evaluate the project

(1) At first, the sets of factors, weights and evaluation are set up.

The 26 categories of 8 small class as a factor set of projects based on the PPP mode of project financing risks are selected: $U=\{U 1, U 2 \ldots, U 26\}$. According to the importance of project financing risk, the weight of each risk is calculated, and the risk of the project can be divided into three levels, namely the evaluation set V: "high risk, medium risk and high risk".

(2) The fuzzy comprehensive evaluation matrix of the individual factors is established in the project

The the degree of membership that the $\mathrm{i}$ in the last step is relative to the $\mathrm{j}$ in the assessment set $\mathrm{V}=$ "risk is greater, the risk of medium, small risk" is $r_{i j}$. After $r_{i j}$ is determined, the value can be given by expert scoring method according to the degree of membership of the factors. When the degree of membership is greater, the value is closer to 1 , whereas the more close to 0 .

(3)Fuzzy comprehensive evaluation matrix of multi factors in the project is built

After the normalization of $\mathrm{B}$, the fuzzy comprehensive evaluation set $\mathrm{B}=\left(\begin{array}{lll}B_{1} & B_{2} & B_{3}\end{array}\right)$ is obtained. And set $\mathrm{B}$ elements in the fuzzy evaluation have been quantified, but at this time elements in the evaluation set $\mathrm{V}$ are not quantified. The financing risk assessment under the PPP mode is still unable to be got a quantitative measure. At this point, the $\mathrm{V}$ begins to be quantified, and quantitative values are found in table 2 :

Table 2. Standard table of quantitative risk.

\begin{tabular}{|c|c|c|c|}
\hline Grade & Greater risk & Medium risk & Less risk \\
\hline assignment & $100--86$ & $85-66$ & $<65$ \\
\hline
\end{tabular}

The $\mathrm{M}$ value is made as the risk assessment results. According to the resulting matrix, $\mathrm{M}=\left\lfloor B, C^{T}\right\rfloor$, which $\mathrm{C} 1=85$, $\mathrm{C} 2=75, \mathrm{C} 3=65$, and finally the size of the risk is determined according to the $\mathrm{M}$ value.

\section{Empirical analysis}

Luohe Huading world port project is a city greening leisure theme park with the entertainment function responsed by the government, and the budget is 800 million yuan. In order to solve the government pressure, the project investment of about 500 million yuan was invited public bidding by PPP financing mode. According to the project risk identification, the risk is divided into 8 first-level indexes and 26 second-level indexes. 


\subsection{Determination of weight of AHP}

According to the evaluation index system in construction of PPP mode, the target layer is set to the financing risk of project PPP financing mode. The first layer is the 8 first-level indexes with political, financial, market, force majeure risks, and second layer is the 26 second-level indexes with policy and legal changes, price risk.

In this paper, the data survey mainly through the expert investigation and questionnaire survey method to determine the weight of the factors, the results of the scoring table 3 :

Table 3. Elements of the scoring table

\begin{tabular}{|c|c|c|c|}
\hline First-level indexes & Fraction & Second-level indexes & Fraction \\
\hline \multirow{2}{*}{ Political risk $\mathrm{B}_{1}$} & \multirow{2}{*}{6} & Policy risk $\mathrm{C} 1$ & 5 \\
\hline & & Law change risk $\mathrm{C} 2$ & 6 \\
\hline \multirow{3}{*}{ Market risk $\mathrm{B}_{2}$} & \multirow{3}{*}{9} & Price risk $\mathrm{C} 3$ & 8 \\
\hline & & Demand risk $\mathrm{C} 4$ & 7 \\
\hline & & Competition risk $\mathrm{C} 5$ & 7 \\
\hline \multirow{2}{*}{ Financial risk $\mathrm{B}_{3}$} & \multirow{2}{*}{6} & Inflation risk $\mathrm{C} 6$ & 4 \\
\hline & & Interest rate risk $\mathrm{C} 7$ & 4 \\
\hline \multirow{2}{*}{ Non class risk B4 } & \multirow{2}{*}{4} & Weather risk C8 & 3 \\
\hline & & Earthquake and other risks C9 & 2 \\
\hline \multirow{3}{*}{ Technology risk B5 } & \multirow{3}{*}{7} & Design technical risk $\mathrm{C} 10$ & 5 \\
\hline & & Construction technology risk $\mathrm{C} 11$ & 6 \\
\hline & & Other reasons for technical risk $\mathrm{C} 12$ & 4 \\
\hline \multirow{7}{*}{ Construction risk B6 } & \multirow{7}{*}{9} & Land relocation and compensation risk $\mathrm{C} 13$ & 4 \\
\hline & & Timely completion risk $\mathrm{C} 14$ & 8 \\
\hline & & Quality risk C15 & 8 \\
\hline & & Cost expenditure risk $\mathrm{C} 16$ & 7 \\
\hline & & Safety accident risk $\mathrm{C} 17$ & 6 \\
\hline & & Private investment default $\mathrm{C} 18$ & 5 \\
\hline & & Contract unit breach of contract C19 & 6 \\
\hline \multirow{4}{*}{ Operational risk B7 } & \multirow{4}{*}{7} & Supply risk C20 & 5 \\
\hline & & Equipment maintenance risk $\mathrm{C} 21$ & 4 \\
\hline & & Operating unit management $\mathrm{C} 22$ & 5 \\
\hline & & Project unit breach of contract $\mathrm{C} 23$ & 3 \\
\hline \multirow{3}{*}{$\begin{array}{l}\text { Environmental class } \\
\text { riskB8 }\end{array}$} & \multirow{3}{*}{3} & Pollution fines $\mathrm{C} 24$ & 4 \\
\hline & & Environmental costs are too high $\mathrm{C} 25$ & 3 \\
\hline & & $\begin{array}{l}\text { To correct the error of investment is too large } \\
\qquad \mathrm{C} 26\end{array}$ & 3 \\
\hline
\end{tabular}


After the hierarchical structure of the project is constructed, the relationship between the elements of the relationship is generally clear. Then the analytic hierarchy process is used to calculate the relative weight of each factor and combined with the level of various factors to conduct a comprehensive assessment, the judgment matrix is as follows:

$$
\begin{aligned}
& A=\left(\begin{array}{llllllll}
1 & 6 / 9 & 1 & 6 / 4 & 6 / 7 & 6 / 9 & 6 / 7 & 6 / 3 \\
9 / 6 & 1 & 9 / 6 & 9 / 4 & 9 / 7 & 1 & 9 / 7 & 9 / 3 \\
1 & 6 / 9 & 1 & 6 / 4 & 6 / 7 & 6 / 9 & 6 / 7 & 6 / 3 \\
4 / 6 & 4 / 9 & 4 / 6 & 1 & 4 / 7 & 4 / 9 & 4 / 7 & 4 / 3 \\
7 / 6 & 7 / 9 & 7 / 6 & 7 / 4 & 1 & 7 / 9 & 1 & 7 / 3 \\
9 / 6 & 1 & 9 / 6 & 9 / 4 & 9 / 7 & 1 & 9 / 7 & 7 / 3 \\
7 / 6 & 7 / 9 & 7 / 6 & 7 / 4 & 1 & 7 / 9 & 1 & 7 / 3 \\
3 / 6 & 3 / 9 & 3 / 6 & 3 / 4 & 3 / 7 & 3 / 9 & 3 / 7 & 1
\end{array}\right) \\
& B_{1}=\left(\begin{array}{lc}
1 & 5 / 6 \\
6 / 5 & 1
\end{array}\right) \\
& B_{2}=\left(\begin{array}{lll}
1 & 8 / 7 & 8 / 7 \\
7 / 8 & 1 & 1 \\
7 / 8 & 1 & 1
\end{array}\right) \\
& B_{3}=\left(\begin{array}{ll}
1 & 1 \\
1 & 1
\end{array}\right) \quad B_{4}=\left(\begin{array}{lc}
1 & 3 / 2 \\
2 / 3 & 1
\end{array}\right) \\
& B_{5}=\left(\begin{array}{ccc}
1 & 5 / 6 & 5 / 4 \\
6 / 5 & 1 & 6 / 4 \\
4 / 5 & 4 / 6 & 1
\end{array}\right) \\
& B_{6}=\left(\begin{array}{ccccccc}
1 & 4 / 8 & 4 / 8 & 4 / 7 & 4 / 6 & 4 / 5 & 4 / 6 \\
8 / 4 & 1 & 1 & 8 / 7 & 8 / 6 & 8 / 5 & 8 / 6 \\
8 / 4 & 1 & 1 & 8 / 7 & 8 / 6 & 8 / 5 & 8 / 6 \\
7 / 4 & 7 / 8 & 7 / 8 & 1 & 7 / 6 & 7 / 5 & 7 / 6 \\
6 / 4 & 6 / 8 & 6 / 8 & 6 / 7 & 1 & 6 / 5 & 1 \\
5 / 4 & 5 / 8 & 5 / 8 & 5 / 7 & 5 / 6 & 1 & 5 / 6 \\
6 / 4 & 6 / 8 & 6 / 8 & 6 / 7 & 1 & 6 / 5 & 1
\end{array}\right) \\
& B_{7}=\left(\begin{array}{cccc}
1 & 5 / 4 & 1 & 5 / 3 \\
4 / 5 & 1 & 4 / 5 & 4 / 3 \\
1 & 5 / 4 & 1 & 5 / 3 \\
3 / 5 & 3 / 4 & 3 / 5 & 1
\end{array}\right) B_{8}=\left(\begin{array}{ccc}
1 & 4 / 3 & 4 / 3 \\
3 / 4 & 1 & 1 \\
3 / 4 & 1 & 1
\end{array}\right)
\end{aligned}
$$

The weights are calculated by the formula mentioned in the former part in this paper, the formula (3) is used to calculate the maximum eigenvalue of the matrix $\lambda_{\max }=8.5834$. And $C I=\frac{\lambda_{\max }-n}{n-1}$, then $C I=\frac{8.5834-8}{8-7}=0.08332$

According to Table 2.1, the average value of random consistency index can be checked $\mathrm{RI}=1.41$.Because $C R=\frac{C I}{R I}=\frac{0.08332}{1.41}=0.059<0.10$, the matrix is fit to the consistency, and the weight of each factor of the first level

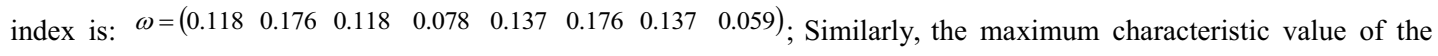
second-level indexes can be obtained: $\lambda_{\max 1}=8.0544, \lambda_{\max 2}=8.7895, \lambda_{\max 3}=8.0852, \lambda_{\max 4}=8.0771$, 
$\lambda_{\max 5}=8.1250, \lambda_{\max 6}=8.0073, \lambda_{\max 7}=8.0981, \lambda_{\max 8}=8.0155$,CI means $C I_{1}=0.07551, C I_{2}=0.08731$, $C I_{3}=0.08013, C I_{4}=0.07892, C I_{5}=0.08455, C_{6}=0.07954, C I_{7}=0.07642, C I_{8}=0.07883$. After the calculation can be obtained CR are less than 0.100 , so all the judgment matrix to meet the consistency test. Second-level indexes of the weight of the elements are:

$$
\begin{aligned}
& \omega_{1}=\left(\begin{array}{llll}
0.455 & 0.545
\end{array}\right) \omega_{2}=\left(\begin{array}{lll}
0.364 & 0.318 & 0.318
\end{array}\right) \omega_{3}=\left(\begin{array}{lll}
0.500 & 0.500
\end{array}\right) \omega_{4}=\left(\begin{array}{lll}
0.600 & 0.400
\end{array}\right) \omega_{5}=\left(\begin{array}{lll}
0.333 & 0.400 & 0.267
\end{array}\right) \\
& \omega_{6}=\left(\begin{array}{lllllll}
0.091 & 0.182 & 0.182 & 0.159 & 0.136 & 0.114 & 0.136
\end{array}\right) \omega_{7}=\left(\begin{array}{llll}
0.294 & 0.235 & 0.294 & 0.176
\end{array}\right) \omega_{8}=\left(\begin{array}{lll}
0.400 & 0.300 & 0.300
\end{array}\right)
\end{aligned}
$$

According to the above calculation, in the project risk of PPP financing model, the market risk and proportion of construction risk is the largest, followed by technical risk, financial risk, political risk. In the study, in the project financing risk process of PPP mode, we should focus on taking into account the large proportion of the risk, and the only way to effectively prevent the risk of the project.

\subsection{Fuzzy comprehensive evaluation of project financing risk}

The 26 risk factors mentioned in this paper is different from the impact of the whole project. According to the different factors, the corresponding weight is given, and the weights of 26 second-level indexes risk are got by the analytic hierarchy process:

$\mathrm{A}=\{0.455,0.545,0.364,0.318,0.318,0.500,0.500,0.600,0.400,0.333,0.400,0.267,0.091,0.182,0.182,0.159,0.136,0.114$ , $0.136,0.294,0.235,0.294,0.176,0.400,0.300,0.300\}$.

And then through finding the project related experts, the expert scoring method is used for these risk factors scoring, scoring table as shown in table 4 .

When the first-level indexes are got matrix, the basic formula $B=\omega \bullet R$ can be calculated by fuzzy comprehensive evaluation:

$$
\begin{gathered}
B_{1}=\omega_{1} \cdot R_{1}=\left(\begin{array}{lll}
0.378 & 0.346 & 0.423
\end{array}\right) \\
B_{2}=\omega_{2} \cdot R_{2}=\left(\begin{array}{ccc}
0.343 \quad & 0.319 & 0.338
\end{array}\right) B_{3}=\omega_{3} \bullet R_{3}=\left(\begin{array}{lll}
0.242 & 0.199 & 0.514
\end{array}\right) \\
B_{4}=\omega_{4} \bullet R_{4}=\left(\begin{array}{lll}
0.314 & 0.259 & 0.427
\end{array}\right) \\
B_{5}=\omega_{5} \bullet R_{5}=\left(\begin{array}{lll}
0.399 & 0.410 & 0.190
\end{array}\right) \\
B_{6}=\omega_{6} \bullet R_{6}=\left(\begin{array}{lll}
0.368 & 0.269 & 0.363
\end{array}\right) \\
B_{7}=\omega_{7} \bullet R_{7}=\left(\begin{array}{lll}
0.249 & 0.284 & 0.467
\end{array}\right) \\
B_{8}=\omega_{8} \bullet R_{8}=\left(\begin{array}{lll}
0.359 & 0.337 & 0.305
\end{array}\right)
\end{gathered}
$$

\begin{tabular}{|c|c|c|c|c|c|c|}
\hline \multirow{2}{*}{$\begin{array}{l}\text { First-leve } \\
1 \text { indexes }\end{array}$} & \multirow{2}{*}{ weight } & \multirow{2}{*}{ Second-level indexes } & \multirow{2}{*}{ weight } & \multicolumn{3}{|c|}{ Comment set } \\
\hline & & & & Greater risk & Medium risk & Less risk \\
\hline \multirow{2}{*}{$\begin{array}{c}\text { Political } \\
\text { risk } B_{1}\end{array}$} & \multirow{2}{*}{0.118} & Policy risk $\mathrm{C} 1$ & 0.455 & 0.322 & 0.375 & 0.303 \\
\hline & & Law change risk $\mathrm{C} 2$ & 0.545 & 0.425 & 0.321 & 0.524 \\
\hline \multirow{2}{*}{$\begin{array}{l}\text { Market } \\
\text { risk } B_{2}\end{array}$} & \multirow{2}{*}{0.176} & Price risk $\mathrm{C} 3$ & 0.364 & 0.442 & 0.239 & 0.319 \\
\hline & & Demand risk $\mathrm{C} 4$ & 0.318 & 0.247 & 0.318 & 0.435 \\
\hline
\end{tabular}

Table 4. Effect of PPP mode on the project financing risk factors scoring table. 


\begin{tabular}{|c|c|c|c|c|c|c|}
\hline & & Competition risk $\mathrm{C} 5$ & 0.318 & 0.325 & 0.412 & 0.263 \\
\hline \multirow{2}{*}{$\begin{array}{l}\text { Financial } \\
\text { risk } \mathrm{B}_{3}\end{array}$} & \multirow{2}{*}{0.118} & Inflation risk $\mathrm{C} 6$ & 0.500 & 0.157 & 0.213 & 0.630 \\
\hline & & Interest rate risk $\mathrm{C} 7$ & 0.500 & 0.327 & 0.275 & 0.398 \\
\hline \multirow{2}{*}{$\begin{array}{c}\text { Non } \\
\text { class risk } \\
\text { B4 }\end{array}$} & \multirow{2}{*}{0.078} & Weather risk $\mathrm{C} 8$ & 0.600 & 0.456 & 0.249 & 0.295 \\
\hline & & $\begin{array}{l}\text { Earthquake and other risks } \\
\text { C9 }\end{array}$ & 0.400 & 0.102 & 0.273 & 0.625 \\
\hline \multirow{3}{*}{$\begin{array}{c}\text { Technolo } \\
\text { gy risk } \\
\text { B5 }\end{array}$} & \multirow{3}{*}{0.137} & Design technical risk $\mathrm{C} 10$ & 0.333 & 0.319 & 0.438 & 0.243 \\
\hline & & $\begin{array}{c}\text { Construction technology } \\
\text { risk } \mathrm{C} 11\end{array}$ & 0.400 & 0.468 & 0.373 & 0.159 \\
\hline & & $\begin{array}{c}\text { Other reasons for technical } \\
\text { risk } \mathrm{C} 12\end{array}$ & 0.267 & 0.397 & 0.432 & 0.171 \\
\hline \multirow{7}{*}{$\begin{array}{c}\text { Construct } \\
\text { ion risk } \\
\text { B6 }\end{array}$} & \multirow{7}{*}{0.176} & $\begin{array}{c}\text { Land relocation and } \\
\text { compensation risk } \mathrm{C} 13\end{array}$ & 0.091 & 0.631 & 0.233 & 0.136 \\
\hline & & $\begin{array}{l}\text { Timely completion risk } \\
\text { C14 } \\
\end{array}$ & 0.182 & 0.732 & 0.138 & 0.130 \\
\hline & & Quality risk C15 & 0.182 & 0.375 & 0.239 & 0.386 \\
\hline & & Cost expenditure risk $\mathrm{C} 16$ & 0.159 & 0.237 & 0.368 & 0.394 \\
\hline & & $\begin{array}{l}\text { Safety accident risk } \\
\text { C17 }\end{array}$ & 0.136 & 0.118 & 0.299 & 0.583 \\
\hline & & $\begin{array}{l}\text { Private investment default } \\
\qquad \mathrm{C} 18\end{array}$ & 0.114 & 0.216 & 0.273 & 0.511 \\
\hline & & $\begin{array}{c}\text { Contract unit breach of } \\
\text { contract } \mathrm{C} 19\end{array}$ & 0.136 & 0.227 & 0.361 & 0.412 \\
\hline \multirow{4}{*}{$\begin{array}{c}\text { Operatio } \\
\text { nal risk } \\
\text { B7 }\end{array}$} & \multirow{4}{*}{0.137} & Supply risk C20 & 0.294 & 0.312 & 0.218 & 0.470 \\
\hline & & $\begin{array}{c}\text { Equipment maintenance } \\
\text { risk } \mathrm{C} 21\end{array}$ & 0.235 & 0.421 & 0.312 & 0.267 \\
\hline & & $\begin{array}{c}\text { Operating unit } \\
\text { management } \mathrm{C} 22 \\
\end{array}$ & 0.294 & 0.128 & 0.275 & 0.597 \\
\hline & & $\begin{array}{c}\text { Project unit breach of } \\
\text { contract } \mathrm{C} 23\end{array}$ & 0.176 & 0.116 & 0.372 & 0.512 \\
\hline \multirow{3}{*}{$\begin{array}{c}\text { Environ } \\
\text { mental } \\
\text { class risk } \\
\text { B8 }\end{array}$} & \multirow{3}{*}{0.059} & Pollution fines C24 & 0.400 & 0.413 & 0.279 & 0.308 \\
\hline & & $\begin{array}{c}\text { Environmental costs are } \\
\text { too high } \mathrm{C} 25\end{array}$ & 0.300 & 0.366 & 0.432 & 0.202 \\
\hline & & $\begin{array}{c}\text { To correct the error of } \\
\text { investment is too large } \mathrm{C} 26\end{array}$ & 0.300 & 0.279 & 0.318 & 0.403 \\
\hline
\end{tabular}

That is: $\mathrm{R}=\left(\begin{array}{lllllllll}B_{1} & B_{2} & B_{3} & B_{4} & B_{5} & B_{6} & B_{7} & B_{8}\end{array}\right)^{T}$. It is calculated that: $B=W \bullet R=\left(\begin{array}{lll}0.401 & 0.362 & 0.375\end{array}\right)$

According to the theoretical part of this paper, the $\mathrm{M}$ value is the result of risk assessment, and then:

$$
\mathrm{M}=\left(B, C^{T}\right)=\left(\begin{array}{lll}
0.401 & 0.362 & 0.375
\end{array}\right)\left(\begin{array}{lll}
85 & 75 & 65
\end{array}\right)^{T}=78.24
$$

Finally, the size of the risk is 78.24 according to the $\mathrm{M}$ value, so the risk of the project is medium. 


\section{Conclusions}

(1) For the assessment and prevention of risk financing project under PPP mode, firsty, the risks of project construction in PPP model is identified. Secondly, the PPP mode of project financing risk index system is established, and the AHP method is used to confirm the weight of each risk factor and clear the proportion, which is conducive to the participation in the project the main risk preventive measures in a timely manner.

(2) The scoring results were calculated and analyzed by using the fuzzy comprehensive evaluation method of expert survey. The risk factors of PPP project financing mode is divided into 8 categories and 26 items, so as to the comprehensive weight of project financing risk factors under the PPP model is obtained. In order to more accurately express the data of the fuzzy parameters of the fuzzy comprehensive evaluation, which can make quantification persuasive, and using fuzzy comprehensive evaluation method has rigorous mathematical logic, scientific and practical.

(3) In this paper, the above comprehensive research method is applied to the Luohe PPP project financing risk management, and the PPP mode of our country under the application of the general engineering project has played an important guiding significance.

\section{References}

1. C. CAO. A Study on Identification of the Risk Factors of Highway Projects with PPP (Public-Private Partneiship) Financing Mode.Jouranl of Chongqing Three Gorges University, 3: 75-78(2013).

2. Y.W. LIU. Management Research of the Financial Risks of Project Financing Based on PPP Model. Value Engineering, 2015(12):16-18.

3. Y.L. YIN, X.L. YIN. Study on Risk Share in PPP Construction Mode of Beijing Metro Line 4. Railway Transport and Economy, 10:6-11(2013).

4. B. AI, X.C. LU..Model comparison and risk prevention of PPP financing of government project procurement. Seeker, 4:19-21(2008).

5. Q.L. KONG. Risk Management of Urban Infrastructure Construction Based on PPP Model. Construction Engineering Technology and Design,10(2015).

6. A. M. WU. Risk Analysis and Prevention of Engineering Project Financing. Architectural knowledge: Academic Journal, 3:249-249 (2013). 